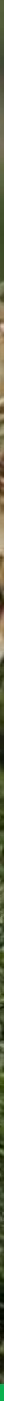

\title{
Vangsten, handel en consumptie van wolhandkrab in Nederland
}

Wim Zaalmink en Piet Rijk 



\section{Vangsten, handel en consumptie van wolhandkrab in Nederland}

Wim Zaalmink en Piet Rijk 
Zaalmink, W. Rijk, P., 2018. Vangsten, handel en consumptie van wolhandkrab in Nederland. Wageningen, Wageningen Economic Research, Rapport 2018-085. 16 blz.; 0 fig.; 4 tab.; 6 ref.

De Chinese wolhandkrab is een exoot die veel in Nederlandse binnenwateren en rivieren voorkomt. In sommige gebieden is er een vangstverbod in verband met het voorkomen van dioxine en pcb's in wolhandkrab. Een risicoanalyse met betrekking tot de consumptie van wolhandkrab in Nederland is noodzakelijk. Hiervoor is het noodzakelijk inzicht te krijgen in welk deel van de Nederlandse vangst in het binnenland wordt afgezet en geconsumeerd. Dit rapport beschrijft de aanlandingen en handelsstromen van wolhandkrab in Nederland. Van de 114 ton die in 2017 is aangeland wordt 85\% geëxporteerd. Het in Nederland blijvende deel vindt vooral zijn weg naar Chinese restaurants en Chinese consumenten.

Trefwoorden: wolhandkrab, aanlandingen, handel, consumenten

Dit rapport is gratis te downloaden op https://doi.org/10.18174/458248 of op www. wur. nl/economicresearch (onder Wageningen Economic Research publicaties).

(C) 2018 Wageningen Economic Research

Postbus 29703, 2502 LS Den Haag, T 07033583 30, E communications.ssg@wur.nl, www. wur.nl/economic-research. Wageningen Economic Research is onderdeel van Wageningen University \& Research.

\section{(cc) BY-NC}

Wageningen Economic Research hanteert voor haar rapporten een Creative Commons Naamsvermelding 3.0 Nederland licentie.

(C) Wageningen Economic Research, onderdeel van Stichting Wageningen Research, 2018 De gebruiker mag het werk kopiëren, verspreiden en doorgeven en afgeleide werken maken. Materiaal van derden waarvan in het werk gebruik is gemaakt en waarop intellectuele eigendomsrechten berusten, mogen niet zonder voorafgaande toestemming van derden gebruikt worden. De gebruiker dient bij het werk de door de maker of de licentiegever aangegeven naam te vermelden, maar niet zodanig dat de indruk gewekt wordt dat zij daarmee instemmen met het werk van de gebruiker of het gebruik van het werk. De gebruiker mag het werk niet voor commerciële doeleinden gebruiken.

Wageningen Economic Research aanvaardt geen aansprakelijkheid voor eventuele schade voortvloeiend uit het gebruik van de resultaten van dit onderzoek of de toepassing van de adviezen.

Wageningen Economic Research is ISO 9001:2008 gecertificeerd.

Wageningen Economic Research Rapport 2018-085 | Projectcode 2282300327

Foto omslag: Shutterstock 


\section{Inhoud}

$\begin{array}{ll}\text { Woord vooraf } & 5\end{array}$

$\begin{array}{lc}\text { Samenvatting } & 6\end{array}$

$\begin{array}{lll}\text { S.1 Belangrijkste uitkomsten } & 6\end{array}$

S.2 Overige uitkomsten $\quad 6$

$\begin{array}{lll}\text { S.3 Methode } & 6\end{array}$

1

$\begin{array}{ll}\text { Inleiding } & 7\end{array}$

$\begin{array}{lll}1.1 & \text { Achtergrond } & 7\end{array}$

$\begin{array}{lll}1.2 & \text { Doelstelling } & 7\end{array}$

$\begin{array}{lll}1.3 & \text { Aanpak } & 7\end{array}$

$2 \quad$ De wolhandkrab $\quad 8$

$\begin{array}{llr}3 & \text { Literatuuroverzicht en data } & 9\end{array}$

$\begin{array}{llr}4 & \text { Interviews } & 10\end{array}$

$\begin{array}{llr}5 & \text { Resultaten } & 11\end{array}$

$5.1 \quad$ Aangelande hoeveelheden en afzetkanalen 11

5.2 Geldopbrengsten 12

$\begin{array}{lll}5.3 & \text { Bestemmingen } & 12\end{array}$

$\begin{array}{lll}5.4 & \text { Consumptie in Nederland } & 13\end{array}$

$\begin{array}{lll}5.5 & \text { Kweek en andere ontwikkelingen } & 13\end{array}$

$\begin{array}{lll}5.6 & \text { Import } & 13\end{array}$

$6 \quad$ Conclusies en aanbevelingen $\quad 14$

$\begin{array}{ll}\text { Literatuur en websites } & 15\end{array}$ 



\section{Woord vooraf}

De Nederlandse Voedsel- en Warenautoriteit (NVWA) heeft Wageningen Economic Research gevraagd een onderzoek uit te voeren naar de handelsstromen van wolhandkrab in Nederland. Dit onderzoek is onderdeel van een risicoanalyse die door de NVWA wordt uitgevoerd, waarbij het van belang is inzicht te hebben in de omvang van de consumptie in Nederland.

De onderzoekers hebben interviews en gesprekken gevoerd met vissers en vertegenwoordigers van visafslagen en handel. Dank aan iedereen die aan het onderzoek heeft meegewerkt.

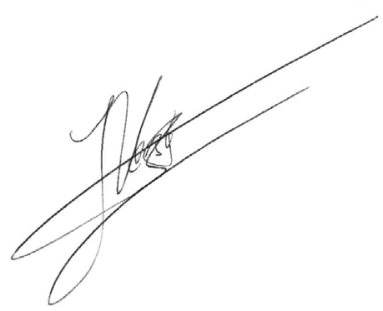

Prof.dr.ir. J.G.A.J . (J ack) van der Vorst Algemeen Directeur Social Sciences Group (SSG)

Wageningen University \& Research 


\section{Samenvatting}

\section{S.1 Belangrijkste uitkomsten}

In 2017 is in Nederland naar schatting bijna 114 ton wolhandkrab aangeland. Hiervan wordt 39\% via de visafslag verhandeld en de overige $61 \%$ gaat naar de groothandel, Chinese handelaren en Chinese restaurants. In totaal blijft 15\% van de aanlandingen in Nederland, wordt 59\% geëxporteerd naar Europese landen en $26 \%$ naar Azië. Consumptie in Nederland vindt vooral plaats door Aziatische bevolkingsgroepen.

\section{S.2 Overige uitkomsten}

Wolhandkrab is een voor vissers aantrekkelijke bijvangst. De opbrengstprijzen zijn gemiddeld 17 euro per $\mathrm{kg}$ met een variatie van 7 euro tot soms 30 euro per $\mathrm{kg}$ gedurende feestdagen zoals het Chinese nieuwjaar. De laatste jaren wordt minder via de visafslag verhandeld, maar meer rechtstreeks via handelaren.

\section{S.3 Methode}

Er zijn weinig statistieken over wolhandkrab voorhanden. Voor het onderzoek zijn interviews gehouden met vissers, handelaren en visafslagen. De verkregen resultaten zijn getoetst met resultaten van voorgaand onderzoek en beschikbare statistieken van de producentenorganisatie van I) sselmeervissers. 


\section{$1 \quad$ Inleiding}

\section{$1.1 \quad$ Achtergrond}

De Chinese wolhandkrab is een exoot, oorspronkelijk afkomstig uit Oost-Azië, die tegenwoordig ook in veel Nederlandse wateren voorkomt. Waar deze soort vroeger door vissers als een vervelende bijvangst werd gezien, vindt de krab nu gretig aftrek onder vooral Chinese bevolkingsgroepen in Europa en Azië. Wolhandkrab brengt gemiddeld ongeveer 17 euro per kg op en wordt daarmee een inkomstenbron voor een aantal binnenvissers in Nederland.

Sinds 1 april 2011 zijn grote delen van de Nederlandse wateren, met name de grote rivieren en de hiermee in open verbinding staande wateren, gesloten voor de visserij op aal en wolhandkrab. Het Nederlandse stroomgebied van de Rijn en Maas kenmerkt zich door verontreiniging van de waterbodem met dioxines en polychloorbifenyl-verbindingen ( $p c b$ 's) als gevolg van historische lozingen. Ook zijn er andere lokale wateren in Nederland buiten dit stroomgebied vervuild. De aal en wolhandkrab in de wateren die zijn gesloten voor de visserij op deze soorten, bevatten een te hoog gehalte aan dioxines en pcb's voor menselijke consumptie.

Het ministerie van Volksgezondheid, Welzijn en Sport heeft recent bureau Risicobeoordeling \& onderzoek (BuRO) van de Nederlandse Voedsel- en Warenautoriteit gevraagd een risicobeoordeling uit te laten voeren voor dioxine en pcb's.

Een onderdeel van deze risicobeoordeling is het verkrijgen van inzicht in de consumptie van wolhandkrab en wolhandkrabdelen in Nederland, en inzicht in productie, import en export om het Nederlandse gebruik vast te kunnen stellen.

\subsection{Doelstelling}

Wageningen Economic Research is gevraagd om inzicht te geven in productie (vangst), export en import van wolhandkrab en de bestemming van wolhandkrab in Nederland, en de trend hiervan in de loop der jaren.

\subsection{Aanpak}

Eerst is literatuuronderzoek uitgevoerd naar marktstudies over wolhandkrab. Vervolgens zijn statistieken geraadpleegd over vangsten, handel en verwerking van wolhandkrab, voor zover beschikbaar. Ter aanvulling daarop zijn telefonische interviews uitgevoerd met sectordeskundigen, binnenvissers, visafslagen en handelaren. Sommige geïnterviewden hebben aanvullende informatie via via e-mail verstrekt. Ten slotte zijn telefonische interviews met Chinese restauranthouders uitgevoerd met het doel om zicht te krijgen op de consumptie van wolhandkrab door Chinese en Nederlandse bevolkingsgroepen. 


\section{De wolhandkrab}

De Chinese wolhandkrab is voor de eerste keer waargenomen in 1912 in de rivier de Wezer in Duitsland. De larven waren per ongeluk vanuit China per schip getransporteerd. Hierna heeft de soort zich waarschijnlijk via de Rotterdamse haven verspreid door het fijnmazig waternetwerk in Nederland. Tegenwoordig kan men de krab vrijwel overal aantreffen in alle Nederlandse grote en binnenwateren.

De Chinese wolhandkrab is in zijn normale volwassen leven een zoetwaterkrab. Hij wordt twee tot vijf jaar oud. Paring vindt in de winter in estuaria en zoete wateren plaats, waarna de vrouwtjes de zee intrekken. Eieren worden dan losgelaten; larven en jonge krabbetjes zoeken vervolgens weer de zoete binnenwateren op (Soes et al., 2007).

Aanvankelijk werd de wolhandkrab door vissers en waterschappen gezien als een plaag. De krabben knipten netten en fuiken open, waardoor de gevangen vis kon ontsnappen (Bakker en Zaalmink, 2012). Vanaf 2000 kregen echter een aantal vissers in de gaten dat er een markt was voor de wolhandkrab, vooral in China en bij mensen van Chinese afkomst in Nederland en elders in Europa. Vooral vanaf 2005 ontwikkelde deze markt zich verder. In toenemende mate werden de wolhandkrabben opgevist en op de markt gebracht. Daarbij gold en geldt nog steeds: hoe groter de krab, des te hoger de prijs. De meeste wolhandkrabben wegen tussen de 100 en 150 gram. De wolhandkrab heeft in het najaar het hoogste gewicht.

Het vissen en vermarkten van wolhandkrabben kende tot 2011 geen restricties. In 2009 is het vangstverbod voor paling in het najaar ingegaan als gevolg van de Europese aalverordening. De wolhandkrab werd dikwijls als nevenvangst bij de palingvangst verkocht. In 2011 werden als gevolg van te veel dioxine en pcb's gebieden in Nederland (vooral de stroomgebieden van de grote rivieren) gesloten voor de vangst van aal en wolhandkrab.

De actuele situatie is zo dat er alleen in het IJ sselmeergebied en omgeving en op andere wateren dan het grote rivierengebied op de wolhandkrab gevist mag worden. Er zijn verschillende manieren om op wolhandkrab te vissen:

a. Met fuiken, vooral gericht op aalvisserij, waarbij wolhandkrab bijvangst is. In het kader van het aalherstelplan is aalvisserij niet toegestaan in de periode van 1 september tot eind november. Met aangepaste fuiken en met een speciale ontheffing mag in de betreffende periode wel met fuiken op wolhandkrab gevist worden.

b. Met staande netten, hoog of laag. Deze worden in de IJ sselmeervisserij vooral gebruikt voor vangst van schubvis (snoekbaars). Wolhandkrab wordt in sommige gebieden veel bijgevangen.

In de periode 1 september - 1 december (wanneer de aalvisserij gesloten is) heeft de wolhandkrab een goed gewicht en brengt dan veel in geld op. Oktober tot en met januari zijn vaak de beste maanden om op wolhandkrab te vissen. De vraag en daarmee de prijs is vaak het hoogst rond het Chinese nieuwjaar (eind januari - begin februari). 


\section{Literatuuroverzicht en data}

In 2012 is door Wageningen Economic Research op verzoek van de kenniskring binnenvisserij een marktverkenning uitgevoerd naar de afzetperspectieven van wolhandkrab. Binnenvissers zagen als gevolg van een beperking van de aalvangsten hun inkomsten teruglopen en zochten naar perspectief voor het vermarkten van wolhandkrab. De conclusie van die studie was dat er een omvangrijke afzetmarkt is voor de Nederlandse wolhandkrab, vooral onder Chinese, Japanse en Koreaanse consumenten in grote Europese steden (Bakker en Zaalmink, 2012).

In 2011 maakte Wageningen Economic Research een overzicht van de sociaal-economische waarde van de binnenvisserij. Daaruit bleek dat de vangsten van wolhandkrab waren toegenomen van 30 ton in 2004 naar 65 ton in 2010 (Zaalmink, 2011).

Uit een in 2013 uitgevoerd onderzoek naar consumptie van wolhandkrab in Nederland (Leeuwen et al., 2013) blijkt dat vooral eerste generatie Chinezen in Nederland wolhandkrab consumeren. De inschatting uit het betreffende onderzoek, op basis van enkele interviews, was dat ongeveer 10 tot $15 \%$ van de Nederlandse vangst in het binnenland werd geconsumeerd door hoofdzakelijk Chinezen. Er zou veel wolhandkrab worden geëxporteerd naar Azië, en enkele Europese landen.

In 2015 is in opdracht van de NVWA een onderzoek uitgevoerd naar de economische waarde van exoten in Nederland. In dit rapport komt naar voren dat de economische waarde van de wolhandkrabvisserij in 2014 ongeveer 1,4 miljoen euro bedraagt. Er zouden ongeveer 50 gezinnen afhankelijk zijn van de inkomsten van wolhandkrab (Rijk et al., 2015).

In een studie naar de economische waarde van de IJ sselmeervisserij (Zaalmink et al., 2017) blijkt dat de vangst van wolhandkrab uit IJ ssel- en Markermeer in 201660 ton zou hebben bedragen met een besomming van 995.000 euro. In deze studie is de aanvoer van wolhandkrab uit andere gebieden dan het IJ sselmeer buiten beschouwing gebleven. 


\section{$4 \quad$ Interviews}

Bij de Rijksdienst voor Ondernemend Nederland (RVO) staan in 2017111 beroepsbinnenvisserijen geregistreerd. Een geregistreerd bedrijf heeft minimaal 250 ha viswater en een minimale omzet van 8.500 euro per jaar, en daarnaast moet het vissersvaartuig zijn ingeschreven in het Nederlands Register van Vissersvaartuigen. Een deel van deze vissers vangt ook wolhandkrabben.

Interviews bij vergunninghouders In 2017 hadden van de 111 geregistreerde binnenvisserijbedrijven 21 bedrijven (19\%) een ontheffing om met aangepaste fuiken het gehele jaar op wolhandkrab te vissen. Zij zijn voor een groot deel van hun inkomen afhankelijk van het vissen op deze krabben. Het betreft ongeveer 45 gezinnen. Om inzicht te krijgen in hun vangsten en afzetkanaal zijn ze allen telefonische benaderd. Van 19 van de 21 bedrijven is informatie verkregen (twee waren niet bereikbaar). De verkregen informatie is vervolgens geaggregeerd voor de gehele groep.

Interviews bij andere vissers

De overige vissers zonder ontheffing mogen met de hiervoor vermelde restricties wel op wolhandkrabben vissen maar niet in de periode waarin het normaal gesproken volgens de vergunning verboden is met de betreffende vistuigen te vissen. Van deze groep zijn 20 vissers telefonisch benaderd en is informatie verkregen over de vangsten en de afzetkanalen. Ook deze informatie is uitgewerkt voor de gehele groep (exclusief de vergunninghouders). Uit de interviews bleek dat slechts een klein deel van deze groep daadwerkelijk wolhandkrabben heeft gevangen en verkocht (30\%).

Informatie van visafslagen

Verdere informatie is verkregen van de Producentenorganisatie van de Nederlandse Vissersbond IJ sselmeer, de IJ sselmeerafslag Urk, visafslag Den Oever, United Fish Auctions (met afslagen in Stellendam, Colijnsplaat en Scheveningen) en de visafslagen in Vlissingen en Breskens (deze twee laatsten hadden geen enkele aanvoer van wolhandkrabben).

Informatie van de vishandel

Van 11 Nederlandse vis(groot) handelaren zijn gegevens gekregen. Twee bleken er totaal niet in te handelen. Een deel van de afzet vindt plaats via Chinese handelaren. Deze laatste groep is niet benaderd omdat geen contactgegevens beschikbaar zijn.

Informatie van Chinese restauranthouders

Er zijn 15 Chinese restauranthouders gebeld in de omgeving van Den Haag en IJ muiden. Hiervan waren er 10 bereid vragen over de consumptie van wolhandkrab te beantwoorden. 


\section{Resultaten}

\subsection{Aangelande hoeveelheden en afzetkanalen}

In totaal werd er door de Nederlandse binnenvisserij bijna 114 ton wolhandkrab aangeland. De meeste wolhandkrabben worden rechtstreeks aan de visserijgroothandel en aan enkele Chinese handelaren verkocht (53\% van het totaal). Via de diverse visafslagen vindt $39 \%$ van de wolhandkrabben zijn weg. Ongeveer $8 \%$ van de wolhandkrabben wordt min of meer rechtstreeks aan de eindgebruiker verkocht. Hieronder zijn ook vele Chinese restauranthouders, waarbij het niet duidelijk is of ze deze zelf consumeren of in hun restaurants serveren. Tabel 5.1 geeft een overzicht van de diverse afzetkanalen.

Tabel 5.1 Afzet van wolhandkrabben, naar afzetkanaal in 2017

\begin{tabular}{lrr} 
Afzetkanaal & x ton & 33,9 \\
Veiling a) & 60,2 & 39 \\
\hline Rechtstreeks naar Nederlandse visserijgroothandel en & & \\
specifieke Chinese handel & 9,6 & $\mathbf{8}$ \\
\hline Rechtstreeks naar eindgebruikers b) & $\mathbf{1 1 3 , 7}$ & $\mathbf{1 0 0}$
\end{tabular}

a) Geaggregeerde opgave vissers (deze berekening kwam vrijwel overeen met de opgaven van de afslagen); b) Winkels, restaurants en consumenten.

Vissers met een ontheffing voor wolhandkrab verkopen relatief meer via de afslag dan de nietvergunninghouders (tabel 5.2).

Tabel 5.2 Geschatte hoeveelheden (in tonnen) en afzetwijze van wolhandkrabben in 2017

\begin{tabular}{lrrrr} 
Afkomstig van & Afslag & Rechtstreeks & Totaal \\
Vergunninghouders & 42,2 & 53,9 & 96,1 \\
\hline Niet-vergunninghouders & 1,7 & 15,9 & \\
\hline Totaal & $\mathbf{4 3 , 9}$ & $\mathbf{6 9 , 8}$ & 17,6 \\
\hline
\end{tabular}

In vergelijking met de resultaten uit 2015, waarbij naar data van 2014 werd gevraagd, lijken er nu meer rechtstreekse verkopen aan de handel te zijn en lijkt er minder naar de afslag te worden aangevoerd. De manier van gegevensverzameling in beide jaren is niet gelijk (er zijn in 2018 meer vissers geïnterviewd dan in 2015).

Van belang bij de interpretatie is ook het feit dat er van jaar op jaar aanzienlijke verschillen kunnen zijn in de hoeveelheden wolhandkrabben die gevist worden. Die heeft vooral te maken met het specifieke groeiseizoen van het jaar waarin de wolhandkrabben al of niet goed gedijen. Vooral de temperatuur van het water is van belang voor deze vangsthoeveelheid.

Een indicatie van de schommelingen over de afgelopen jaren leveren de gezamenlijke aanvoergegevens op de afslagen van de visafslagen Urk, Den Oever en Stellendam. Tabel 5.3 geeft hiervan een overzicht. 
Tabel 5.3 Aanvoer van Chinese wolhandkrab op de visafslagen in Urk, Den Oever en Stellendam samen (tonnen per jaar)

\begin{tabular}{lr} 
Jaar & $\begin{array}{r}\text { Aanvoer van Chinese wolhandkrab op de } \\
\text { visafslagen (tonnen per jaar) }\end{array}$ \\
\hline 2012 & 103 \\
\hline 2013 & 85 \\
\hline 2014 & 62 \\
\hline 2015 & 30 \\
\hline 2016 & 40 \\
\hline 2017 & 43 \\
\hline
\end{tabular}

\subsection{Geldopbrengsten}

De marktprijs voor de wolhandkrab varieert sterk binnen een jaar. In het voorjaar en zomer zijn de prijzen relatief laag; de krabben zijn dan doorgaans ook minder groot en de vraag is lager. De prijzen zijn dan rond de 7 à 10 euro per kilo. Tussen 1 september en 1 december zijn de afzetprijzen een stuk hoger: gemiddeld zo'n 20 à 22 per kilo. Ook zijn er soms uitschieters tot 30 euro per kilo. Dit komt vooral door het hogere gewicht per krab en de grotere vraag vanuit China. Op de visafslag op Urk is in 2017 een gemiddelde prijs over het hele seizoen betaald van 17,44 euro per kilo. De gemiddelde prijzen over 2015 en 2016 wijken hier niet veel van af (respectievelijk 17,67 en 17,00 euro per kilo).

Uitgaande dat de prijzen op de afslag richtinggevend zullen zijn voor de prijzen die elders betaald worden kan de totale jaarlijkse economische verkoopwaarde voor de vissers gesteld worden op ongeveer 2,0 miljoen euro.

\subsection{Bestemmingen}

Uit de interviews blijkt dat het overgrote deel (85\%) van de Nederlandse wolhandkrab wordt geëxporteerd naar de Chinese gemeenschappen en restaurants in zowel de Europese Unie als naar China (vooral Hongkong). De wolhandkrab die in Nederland blijft heeft de Chinese gemeenschappen en Chinese restaurants als eindbestemming. Andere bestemmingen zijn in de interviews niet genoemd.

Tabel 5.4 Export van wolhandkrab naar bestemming

\begin{tabular}{lll} 
Bestemming & Hoeveelheid (ton) & Percentage \\
Nederlandse binnenlandse markt & 17 & 15 \\
\hline Europese landen & 67 & 59 \\
\hline Azië (vooral Hongkong) & 30 & 26 \\
\hline Totaal & $\mathbf{1 1 4}$ & $\mathbf{1 0 0}$ \\
\hline
\end{tabular}

Bovengenoemde percentages zijn zo goed mogelijk geschat. Een manco is dat er geen interviews zijn gedaan bij Chinese handelaren. Deze waren niet bekend bij de geïnterviewden of men wilde deze niet bekend maken. 


\subsection{Consumptie in Nederland}

Uit de telefonische interviews met Chinese restauranthouders bleek het volgende:

Van de 15 restauranthouders die zijn gebeld waren er 10 die meer wilden vertellen over de consumptie van wolhandkrab. Deze restauranthouders waren allen van Chinese afkomst. Ze zijn bekend met het fenomeen wolhandkrab en consumeren deze zelf ook regelmatig, samen met hun familie. Bij geen van de restaurants staat wolhandkrab op de menulijst. De helft geeft aan dat wolhandkrab op verzoek besteld kan worden. De gesproken restauranthouders vinden het een heerlijk product, het smaakt soms wat zoetig en is op zijn lekkerst in het najaar. Volgens hen eten Nederlanders geen wolhandkrab. In de restaurants zelf worden ze niet door Nederlanders geconsumeerd. Als reden gaven ze op dat het teveel werk zou zijn om te eten ('te veel gehannes' werd gezegd), Nederlanders willen liever een gerecht dat gemakkelijk te eten is. Daar komt bij dat het voor Nederlanders een onbekend gerecht is.

\subsection{Kweek en andere ontwikkelingen}

Een aantal jaren is er in Wieringen een proef gestart met het kweken van wolhandkrabben, in combinatie met de teelt van sla, karpers en de zwarte soldaatvlieg. In een zo goed als gesloten systeem worden kleine wolhandkrabben, met ontheffing opgevist op specifieke bestekken in het IJ sselmeer, grootgebracht waarbij onder andere de larven van de zwarte soldaatvlieg als voeding dienen. De proef is nog in een experimentele fase, en de wet- en regelgeving over dit experiment is nog niet duidelijk. Betrokken partijen zijn Rijkswaterstaat, Deltares, Meromar, Zilt proefbedrijf Texel en Sportvisserij Nederland. De zogenoemde Proeftuin Achteroever Wieringermeer is gelegen in een gebied met een dubbele dijk tussen Medemblik en Den Oever. Op dit moment is het gebied uitgebreid tot 5 ha, en er is inmiddels 1.000 kilo wolhandkrab gekweekt (Bron: internet en informatie uit de interviews).

In het verleden heeft ook onderzoek plaatsgevonden naar de mogelijkheid om de delen van de wolhandkrab waarin zich geen toxinen bevinden te scheiden van de delen waarin zich deze wel bevinden. Omdat de Chinese consument (en daarmee ook de handel) de wolhandkrab levend wil zien en bereiden is dit experiment stopgezet (Bron: interviews).

Omdat nu in delen van het land niet gevist mag worden op de wolhandkrab is de inschatting dat er minimaal 75 ton per jaar niet opgevist wordt (Bakker en Zaalmink, 2012).

\section{$5.6 \quad$ Import}

In dit onderzoek zijn geen aanwijzingen gevonden dat er import van wolhandkrab plaatsvindt. Eurostatdata tonen dat alleen aanlanding van wolhandkrab in Nederland plaatsvindt en niet in andere landen. 


\section{Conclusies en aanbevelingen}

\section{Aanlanding van wolhandkrab in Nederland}

In totaal werd in 2017 door de Nederlandse binnenvisserij bijna 114 ton wolhandkrabben aangeland. Deze 114 ton vertegenwoordigt een waarde van bijna 2 miljoen euro.

\section{Handelskanalen wolhandkrab}

De meeste wolhandkrabben worden rechtstreeks aan de visserijgroothandel en aan Chinese handelaren verkocht ( $53 \%$ van het totaal). Via de diverse visafslagen vindt $39 \%$ van de wolhandkrabben zijn weg. Ongeveer $8 \%$ van de wolhandkrabben wordt min of meer rechtstreeks aan de eindgebruiker verkocht. Hieronder zijn ook vele Chinese restauranthouders.

\section{Bestemming van wolhandkrab}

Het overgrote deel van de gevangen Nederlandse wolhandkrab wordt geëxporteerd. Dit vooral naar de Chinese gemeenschappen en restaurants in zowel de Europese Unie als naar China (vooral Hongkong). De wolhandkrab die in Nederland blijft heeft doorgaans ook de Chinese gemeenschappen en Chinese restaurants als eindbestemming. Er zijn geen aanwijzingen gevonden dat de wolhandkrab op de menukaart van Chinese restaurants staat en dat Nederlandse bezoekers wolhandkrab consumeren. Op basis van de interviews met vissers en groothandel krijgt de totale opgeviste wolhandkrabpopulatie de volgende bestemmingen:

- 59\% wordt geëxporteerd naar andere Europese landen

- 26\% wordt geëxporteerd naar Azië (vooral naar Hongkong)

- $15 \%$ heeft als bestemming de Nederlandse binnenlandse markt.

\section{Aanbeveling}

In dit onderzoek is geen grootschalige informatie verzameld over de consumptie van wolhandkrab in Nederland. Uit een beperkt aantal interviews blijkt dat consumptie in Nederland vooral door Aziatische (Chinese) bevolkingsgroepen plaatsvindt. Om hier zekerheid over te krijgen is meer onderzoek nodig naar de consumptie van wolhandkrab in Nederland. Dit zou kunnen gebeuren via een grootschalige (mondelingen en/of schriftelijke) enquête bij Chinese restaurants en handelaren. 


\section{Literatuur en websites}

Bakker, T. en W. Zaalmink, 2012. De wolhandkrab, een Hollandse exoot. Een marktverkenning. LEIrapport 2012-006, juli 2012. LEI Wageningen UR, Den Haag.

Leeuwen, S.R.J., P. Stouten, B.W. Zaalmink en L.A.P. Hoogenboom, 2013. Consumptie van Chinese wolhandkrab in Nederland. RIKILT Rapport 2013.018. RI KILT Wageningen UR, Wageningen.

Rijk, P., M. Turenhout en B.W. Zaalmink, 2015. Socio economic value of non indigenous species in the Netherlands. LEI nota 2015-095, LEI Wageningen UR, Den Haag.

Soes, D.M., P.W. van Horssen, S. Bouma en M.T. Collembon, 2007. Chinese wolhandkrab. Een literatuurstudie naar ecologie en effecten. Bureau Waardenburg B.V., rapport nr. 07-234, 18 december 2007, Culemborg.

Zaalmink, B.W., 2012. Quick scan Nederlandse binnenvisserij 2011. Sociaal economische ontwikkelingen. LEI-nota 11-120, november 2011. LEI Wageningen UR, Den Haag.

Zaalmink, B.W., H. Prins en B. Janssens. Economische waarde IJ sselmeervisserij, 2017. Notitie met betrekking tot de vaststelling van vergunningen en merken. Nota 2017-085, Wageningen Economic Research, oktober 2017. 
Wageningen Economic Research Postbus 29703

2502 LS Den Haag

T 0703358330

Ecommunications.ssg@wur.nl

www. wur. nl/economic-research

Wageningen Economic Research NOTA

2018-085
De missie van Wageningen University \& Research is 'To explore the potential of nature to improve the quality of life'. Binnen Wageningen University \& Research bundelen Wageningen University en gespecialiseerde onderzoeksinstituten van Stichting Wageningen Research hun krachten om bij te dragen aan de oplossing van belangrijke vragen in het domein van gezonde voeding en leefomgeving. Met ongeveer 30 vestigingen, 5.000 medewerkers en 10.000 studenten behoort Wageningen University \& Research wereldwijd tot de aansprekende kennisinstellingen binnen haar domein. De integrale benadering van de vraagstukken en de samenwerking tussen verschillende disciplines vormen het hart van de unieke Wageningen aanpak. 



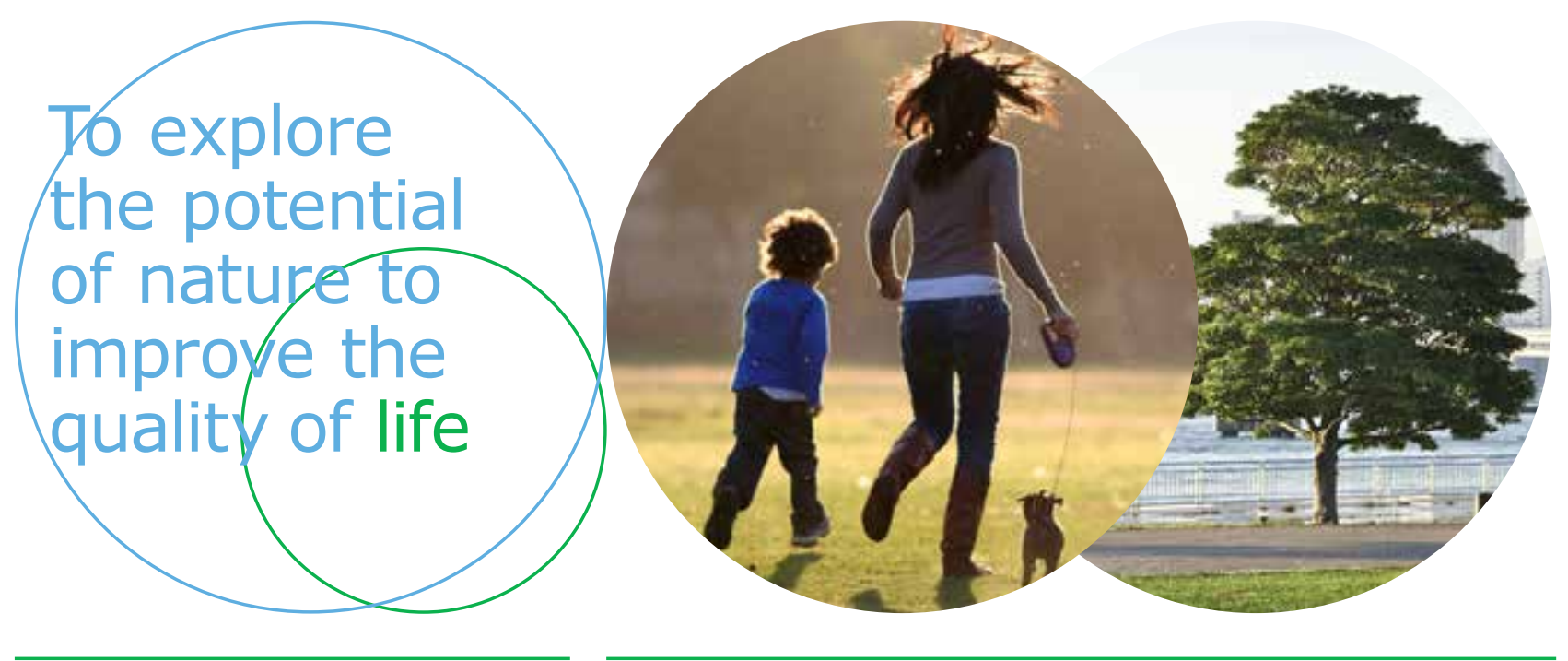

Wageningen Economic Research Postbus 29703

2502 LS Den Haag

E communications.ssg@wur.nl

T+31(0)7033583 30

www.wur.nl/economic-research

Nota 2018-085
De missie van Wageningen University \& Research is 'To explore the potential of nature to improve the quality of life'. Binnen Wageningen University \& Research bundelen Wageningen University en gespecialiseerde onderzoeksinstituten van Stichting Wageningen Research hun krachten om bij te dragen aan de oplossing van belangrijke vragen in het domein van gezonde voeding en leefomgeving. Met ongeveer 30 vestigingen, 5.000 medewerkers en 10.000 studenten behoort Wageningen University \& Research wereldwijd tot de aansprekende kennisinstellingen binnen haar domein. De integrale benadering van de vraagstukken en de samenwerking tussen verschillende disciplines vormen het hart van de unieke Wageningen aanpak. 